\title{
Research on Development Problems of Shared Cars in China*
}

\author{
Hang Gao \\ School of Business \\ Shandong University of Political Science and Law \\ Jinan, China
}

\begin{abstract}
In recent years, the sharing traffic develops rapidly under the background of the continuous development of mobile internet technology and the gradual enhancement of citizens' awareness of green travel. Shared cars provide green travel services in the market way, and they can generalize new energy vehicles. The extensive use of shared cars can make full use of big data, internet, artificial intelligence and other technologies to optimize urban space layout and alleviate traffic congestion. However, there are still many problems in the development of shared cars in China, such as imperfect laws and policies, lagging management models and unbalanced development of supporting services. The government and enterprises should actively work together to explore the development model of shared cars that suits China's national conditions, and promote the green travel service system with "public transportation plus sharing transportation" as the main body.
\end{abstract}

Keywords—shared car; sharing economy; green travel; Internet

\section{INTRODUCTION}

The growth speed of sharing economy in China is very fast, and it has penetrated to the traffic, housing, food, education, medical and other fields. As the most important component of sharing economy, shared cars are growing rapidly. Sharing cars can improve the use efficiency of vehicles, ease traffic congestion and environmental pollution, and make people have more choice of travel ways. Although shared cars are developing rapidly in China, people's understanding of shared cars is not enough, and the development of them still exist some limitations. Therefore, this paper will combing the current situation, models, growth bottlenecks and development countermeasures of shared cars, this to promote the development of sharing cars has the positive significance, and this research has positive significance for promoting the development of shared cars.

\section{THE CURRENT SitUATION OF THE DEVELOPMENT OF SHARED CARS}

\section{A. Rapidly Growth of Market Size}

The development of shared cars in China is relatively late, but the growth rate and market scale have grown rapidly. In 2017, the number of people using shared cars in China was

\footnotetext{
*Fund: This study is funded by youth academic innovation team of
} management science and engineering of SUPL. close to 400 million. About $51 \%$ of the clients used shared cars apps at least once a week. The stickiness of users continues to increase, and solid consumption habit has been cultivated. Carsharing travel has rapidly grown to 1.77 billion orders per year, creating 5.5 million jobs and attracting 150 billion Yuan in investment. It is still accelerating and shows strong vitality. Related data shows that its market volume is expected to reach 600 billion Yuan by 2020. In recent years, shared cars have prospered in China, playing a positive role in promoting green travel and reducing pollution emissions of motor vehicles.

\section{B. Gradual Introduction of Government Policies}

On the legality of internet car rental, the State Information Office organized a news conference on taxi industry reform on July 28, 2016. The conference formally issued new regulations on taxi reform. The conference produced two documents named "Guiding Opinions on Deepening Reform and Promoting the Healthy Development of Taxi Industry" and "Temporary Regulation on the Operation and Service of Internet Car Rental". For the first time, the document clarified the legal status of internet car rental, and the eligible private car can be operated on the car rental platform. The conference made the regulatory model for internet car rental, giving it legal status and supporting its healthy development.

By the end of 2017, 18 major cities in the country have introduced new regulations about internet car rental, and the intensity of policies varies from place to place. For example, Beijing, Shanghai and other cities implement the "double limit" policy, which are "vehicles must be restricted to local license plates" and "drivers must be restricted to local household registration". On the one hand, the policy is designed to ensure safety and ease congestion. On the other hand, the policy is also to control the size of the population and solve the employment problem of local residents. By contrast, the new rules in other non-mega-cities are looser, but basically require giving priority to public transport and keeping taxi development at an appropriate level. In order to optimize their transport structure, most of these cities actively encourage the use of new energy vehicles.

\section{Initial Formation of Time-sharing Leasing Pattern}

At present, in the car rental industry, the main enterprises include state-owned enterprises like Beijing Shouqi Group and Shanghai Volkswagen Rental, private enterprises like 
Shenzhou car rental, Yihai car rental, and Zhizun car rental, and foreign-funded enterprises like Avis-Anjiao and Arval.

Among state-owned enterprises, Beijing Shouqi Group is a typical representative enterprise in car long-and-short leasing service industry. In 2016, Gofun Travel, a new energy timesharing service owned by Shouqi Group, was launched, targeting the post-85th generation of young fashions. In foreign-owned and sino-foreign joint ventures, Shenzhou Car Rental has an absolute competitive advantage in the car rental industry. It aimed at personal and corporate users. By the end of 2017, Shenzhou Car Rental had 764 direct service outlets in 103 major cities in China, with a total fleet of 99727 vehicles and 11 million registered members, making it a leading enterprise in the internet car rental industry of China.

In 2016, internet car time-sharing lease market of China accelerated its development. Gofun Travel, EZZY and other brands emerged. In June of the same year, E-xiangtiankai and EVCARD were merged into World Carriage. This is an important attempt to combine the resource advantages of car enterprises with the advantages of internet enterprises. At present, although there are many companies participating in the vehicle time-sharing leasing business, the market is in the stage of fragmentation due to the limitation of scale and the big differences of each strategy.

As a new service mode, time-sharing car rental service is in the period of rapid development. EVCARDU, Gofun, Green Dog Rental and so on are starting to market layout, and there will still be a large number of enterprises to carve up the market in the future.

\section{Rapid Development of Ride-hailing}

Currently, the online taxi industry in the sharing travel service industry, Didi and Uber are typical companies. Basically, the domestic market has formed a unique market competition pattern, and the leader is Didi. In the field of tailored car and car pooling, Didi, Shenzhou and Uber are typical enterprises, and this field is also in a multi-platform coexistence of competition.

From the perspective of concentration, internet car rental core enterprises, such as Didi, Shenzhou and Yidao, occupy relatively strong market dominance. Didi accounted for $54 \%$ market share of China, and integrated Uber's business in China in July 2016. Shenzhou and Yidao respectively have covered more than 60 cities and 57 cities in China. According to the data released by Yiguan, the market scale of Chinese internet tailored car rental reached 86 billion Yuan in 2017, up 51 percent from 2016. In 2020, the market scale of Chinese internet tailored car rental will reach 160 billion Yuan, but the overall scale is still not able to meet the demand of the sharing car market.

\section{THE Business MOdels OF SHAREd CARS IN CHINA}

With the promotion of mobile internet technology, the car sharing business has been rapidly popularized and developed. Shared cars gradually formed two types of business models, namely the internet car booking and internet car rental. Among them, internet car booking gradually evolved the business model of ride-hailing and car-pooling. Internet car rental gradually evolved out of the business model of P2P car rental and time-sharing lease.

\section{A. Internet Car Booking}

There are two main types of internet car booking: ridehailing and car-pooling. However, after the local governments issued regulations to regulate the shared car platforms, carpooling based on the $\mathrm{C} 2 \mathrm{C}$ model was restricted. The representative enterprise of $\mathrm{C} 2 \mathrm{C}$ Model is Didi. $\mathrm{C}$ refers to the consumer, and $\mathrm{C} 2 \mathrm{C}$ is the e-commerce between the individual and the individual. Didi builds a platform between consumers and consumers, more in line with sharing economy. In $\mathrm{C} 2 \mathrm{C}$ mode, traders are divided into three parts: seller, buyer and platform. The seller is a private car driver, the buyer is a passenger, and the product itself exists as a platform. As a middleman, the platform builds a profit model through the consolidation of stock and expansion of the increment.

1) Ride-hailing: Ride-hailing is the abbreviation of taxi booking. It is based on internet technology to build a service platform and access qualified vehicles and drivers. The platform integrates supply and demand information and provides a non-cruise taxi booking service. The definition of "ride-hailing" not only reflects the nature of taxi, but also reflects the characteristics of its new form of business. Ever since the advent of the ride-hailing, it has been at the forefront of the storm under pressure from all sides. First, the traditional taxi industry strike to resist the development of ride-hailing. Second, there is some public opinion questioning that ridehailing car is illegal and it should not exist. Third, in order to protect the interests of the original taxi enterprises, the local government begins to strike out ride-hailing. In the face of these external pressures, ride-hailing platforms have to face the competition of survival brought by the expansion of competitors.

At present, the domestic market for ride-hailing has entered the oligopoly stage. The four giant companies split up most of the market share. The type of company assets can be divided into light asset type, heavy asset type and mixed type. Didi and Uber belong to light assets, Shenzhou belongs to heavy assets, and Yidao belongs to the mixed model. By the end of 2017, Didi had a 56.6\% market share in China's ride-hailing market, with Shenzhou ranking second with $29.9 \%$. According to industry research reports, Didi has the highest market share of ride-hailing apps.

2) Car pooling: The Chinese government has issued a policy to promote the development of internet car booking. Car pooling requires that the ride-sharing service provider release travel information in advance. People with the same route choose to take the car of the car pooling service provider. Under the shared travel mode, passengers need to share part of the travel costs.

The core of car-pooling products is that passengers have similar travel routes. The platform matches passengers on the same or close routes to increase the number of passengers sharing the cost of single-person travel. The essence of platform service is to provide travel information service and 
reduce information asymmetry. At present, the two main carpooling service models are private car sharing and bus sharing. The former is represented by Dida car-pooling, and the latter is by Didi bus. The new car pooling rules define access conditions and application procedures, and encourage more part-timers with legitimate jobs to switch to car-pooling platforms. With the implementation of the new government policy, the polarization between ride-hailing drivers and carpooling owners will become more and more obvious in the future.

\section{B. Internet Car Rental}

1) P2P car rental: In car-sharing activities, car owners can use platforms to rent out their idle cars. Renters use internet to search for cars they like, but ownership of the cars still belongs to the owners. After the launch of PP car rental in 2013, P2P car rental mode was quickly accepted by the market and became a hot spot of capital pursuit. P2P car rental mode connects the idle vehicles of private car owners and car rental demand through the platform. The advantages of this model are light assets, larger profit space and strong expansionary. The cost of P2P car rental is more than $30 \%$ lower than that of traditional car rental because of the revenue generated by the idle time of private vehicles. The range of vehicle choice is wider and it is more convenient to pick up and return the car.

How to ensure the success rate of placing orders and the standardization of services have become the main difficulties. In addition, the "car-person separation" mode of P2P car rental has more problems in risk control, and the potential risk of car owners is relatively high. Disputes may arise in violation of regulations, scrapes, accidents, refueling and other links. How to ensure their own interests has become the main concern of private car owners. The current practice of PP car rental is to adopt the same method as traditional leasing companies in risk control, verifying the driving license and driving license. In addition, the online credit management system is established through the user mutual assessment mechanism, trying to solve the risk problem by means of the internet.

2) Time-sharing lease: Time-sharing lease business means that consumers rent cars provided by suppliers at the starting point in "hours" or "minutes" and return the vehicles near the end point. Time-sharing lease service is mostly used to meet the demand of personal short-time vehicle, and it requires flexible vehicle time. Auto manufacturing enterprises put the produced vehicles into time-sharing lease, which not only saves cost, but also promotes the sale of cars. Most of the vehicles used in the time-sharing lease sector are new energy vehicles. The time-sharing lease mode enables people to experience the new energy vehicles and realize the rapid promotion of new energy vehicles. At the same time, leasing enterprises actively expand the mobile-end reservation and payment ratio, and the way of interconnection is gradually improved.

At present, the key point of time-sharing lease is that its pricing mode is mainly time-oriented, and mileage valuation is supplementary, complementary with the traditional taxi pricing method. In terms of layout, in the initial stage of limited network and vehicle size, time-sharing lease companies are preferred in suburban areas such as airports, industrial parks and campuses far away from urban areas. They provide transportation schemes for long distance fixed routes from urban to suburban areas, and try to gain market share in the competition with taxis through the advantages of billing, and lay the foundation for development.

\section{StakeHolder ANALYSIS OF SHARED CARS}

\section{A. Traditional Car Rental Companies}

While traditional car rental companies are losing the market of personal driving and short-term rent, they are also gradually losing the field of corporate car rental. In order to cope with the erosion of the traditional car rental market by tailored cars, the traditional car rental companies have transformed into the tailored car market. On the one hand, leading car rental companies such as Shenzhou and Yihai have established their own tailored car platforms due to their relatively strong financial strength and abundant car resources. They use the asset-heavy model to compete with online ride-hailing platforms such as Didi. On the other hand, small and mediumsized leasing companies with relatively weak financial strength have adopted a cooperative approach with online car-hailing platforms such as Didi and put their vehicles on these platforms to recruit drivers to drive. This can greatly improve the efficiency of the use of vehicles, and car rental companies can also obtain stable rental and management fees.

\section{B. Automobile Manufacturing Companies}

In order to cope with the opportunities and challenges brought by car sharing, traditional car manufacturers accelerate the layout of car sharing area, change the traditional sales and business model, and change from "providing car products" to "providing travel services". Chery, Changan, Geely, BYD and other complete car companies have been testing mobile travel. For vehicle manufacturers, they can build vertical ecological circle through mobile travel, give full play to the advantages of vehicle sources, provide vehicles with preferential prices, and reduce the use cost of vehicles to some extent. They can also develop specific models to meet the needs of mobile travel platforms and improve overall competitiveness. On the other hand, with the help of the vehicle promotion on the mobile travel platform, automobile manufacturers can rent vehicles for sale, which can improve the road visibility of vehicles, and it is also a long-term cultivation of enterprise image and customer use habits.

\section{Car-hailing Platforms}

First, the number of mobile travel platform participants is increasing and the competition is becoming increasingly fierce. The main competitors of domestic shared car platforms are Didi, Uber, Shenzhou and Yidao. According to the data of Yiguan Think-tank, active user coverage of tailored car from Didi, Shenzhou and Yidao was $84.2 \%, 14.9 \%$ and $4.9 \%$ respectively in 2017. Second, it puts forward higher requirements on the technical and management level of mobile travel platforms. In the blueprint for future urban transportation in China, a successful urban travel service provider and 
platform needs to be in line with the development trend of mobile internet and sharing economy. Mobile travel platforms need to be equipped with leading mobile internet technology and resource matching capability based on big data and cloud computing. Third, the future profit model of online ride-hailing platform should be diversified. Up to now, the domestic mobile travel service platform is basically in "burning money" stage, and has not yet realized the profit. In addition to service revenue sharing and platform information fee collection, how to maximize the business value of user traffic and increase revenue channels is a thorny issue which all platforms are facing.

\section{Financial Institutions}

At present, China's car sharing market is still in its infancy, with huge room for development. At the present stage, the main bodies for car sharing services, such as individuals, car rental companies, mobile travel platforms or vehicle factories, are mostly purchasing cars by themselves. This creates a large footprint of its own capital, limiting its network layout and fleet size. In terms of vehicle resources, car management parties such as car rental companies can cooperate with financial institutions such as finance leasing companies. The cooperation method is that the finance leasing company purchases vehicles in batches and car management parties pay the rent every month. This can not only ease the cash flow pressure of car management parties, but also rapidly expand its fleet size and improve its operation capacity. The development of car sharing market brings new market space to financial institutions. Financial institutions need to innovate financial products constantly to meet the financial needs of participants in the car sharing market in combination with the new business models of car sharing.

\section{Problems In the DeVElopment OF Shared CARS IN CHINA}

The emergence of shared cars has provided great opportunities for China to explore the green travel model, but there are also some outstanding problems.

\section{A. Insufficient Governmental Polices and Support}

Relative to the rapid development of internet technology, the formulation of relevant laws and regulations on internet is lagging behind. Most of the existing laws and regulations are the product of the industrial age. These regulations do not encourage innovation and cannot continue to play an effective regulatory role. As a new public transportation mode, shared cars have put forward new requirements and challenges to the existing policies.

Currently, the lack of a national top-level design for shared cars in China has led to different requirements on key issues such as market access and vehicle standards. The lack of innovation in management mode leads to the poor development of shared traffic and affects the user experience. As a new model of "internet + " in the field of transportation, Shared vehicles are mainly driven by the attention of capital market. While promoting the rapid development of shared traffic, certain blindness also exist in capital, which brings problems such as unbalanced development and vicious competition. Under the circumstances of increasingly scarce urban space resources and increasingly serious traffic externalities, the government urgently needs to promote the healthy and orderly development of the shared car industry through policy guidance.

\section{B. Higher Operation Costs}

At present, the shared car enterprise is based on the heavy assets mode, and the capital requirement of the enterprise is very high. Companies need to buy new cars, set up service stations, build parking lots and hire employees at the beginning of the car sharing service. Car purchase costs, land costs, personnel costs and management costs, all require huge startup funds.

The operating cost of shared cars mainly includes automobile purchase fee, automobile insurance fee, relevant facility construction fee, software development operation fee and relevant staff capital. If the scope of operation is small, it will take a long time for the company to generate profits. Without the corresponding income, the company cannot promote the development of related facilities and shared cars. Shared car companies have high operating costs, so it takes a long time to develop before they can start making profits.

\section{Many Operation Risks}

Currently, shared car enterprises in China usually operate in the "asset-heavy" mode, with huge capital investment in the early stage. After fierce market competition, several operating enterprises have closed down. Due to the lack of complete withdrawal mechanism, user deposit return and vehicle disposal become social problems. In addition, due to the high value of some rental vehicles, enterprises have some difficulties in vehicle control. At the same time, the imperfect social and industrial credit system leads to vehicle theft and malicious damage, which also brings higher business risks.

The circular economy industrial chain of shared cars is not perfect. The recycling economy and recycling industry chain of shared cars have not been formed yet, and the recycling market demand of scraped Shared vehicles is not strong. This results in a large number of abandoned shared cars being left unattended, which wastes resources and occupies urban space. In the disposal and recycling of abandoned vehicles, the responsibility restraint system and effective incentive mechanism for producers and operators are still lacking.

\section{Difficulty in Parking}

Car parking covers a large area. The parking of shared cars will also be a problem when private car parking spaces are relatively tight. According to data released by the national development and reform commission, the ratio of cars to parking spaces in China's big cities is about 1:0.8, while that of small and medium-sized cities is about 1:0.5. Conservatively, there is a gap of more than 50 million parking spaces in China. It is certainly not very optimistic that such a tight space can be spread out among the shared cars. Due to the shortage of parking space in some cities, the shared car parking space is not guaranteed, and a large number of disorderly parking 
places are located in the central area of the city. Some cities have adopted simple measures such as "no peers" and "no parking" for shared cars in certain areas, rather than adjusting space allocation. This is contrary to the policy direction of green travel.

In big cities, "one turnip, one pit" parking Spaces are already tight in high-density urban areas. However, creating a separate parking area for "shared cars" is also a challenge for city managers. The number of shared car parking lots is small, and most users find it more difficult to find a parking space when using shared cars, which reduces the user experience to some extent.

\section{E. Unused Consumption Habits}

On the demand side, consumers' lack of cognition and understanding is the primary obstacle to overcome in the use of shared cars. In addition, a strong desire to own private cars is another obstacle, especially in China. Fifty-nine percent of Chinese consumers consider owning a private car an important status symbol, and they regard owning a private car as an embodiment of realizing their own value. Moreover, low risk tolerance is also a major obstacle to the development of car sharing. Fifty-one percent of Chinese consumers prefer to borrow a friend's car when they don't own one. In the event of an accident, this reduces their risk in terms of the amount of compensation and the law.

\section{Policy Suggestions ON THE DeVelopment OF SHARED CARS IN CHINA}

\section{A. Consummating Relevant Laws and Regulations}

The relevant government departments should give sufficient adjustment and development time to the market during the development of shared cars. The government should also grasp the rare development opportunities brought about by technological innovation and give policy norms in the development process.

First, the legal system should be established and perfected. The legislature should change the traditional economic thinking of regulation. They should constantly improve relevant laws and regulations according to the characteristics of the sharing economy and the new problems in the development process of sharing cars, so as to create a good market environment for the development of sharing cars. Second, the compulsory insurance system should be implemented. The regulatory authorities should actively investigate relevant responsible groups, such as shared car enterprises and insurance companies, and give guidance on legal aspects. Regulators should force sharing platforms to introduce detailed insurance regulations. Third, the government should include shared traffic development in the urban traffic development plan. The Chinese government can guarantee the healthy development of shared cars through the preferential policy of land transfer, the policy support of loan, the supply of license plates and parking support.

\section{B. Perfecting the Construction of Credit System}

First, Credit system should be improved and a reasonable reward and punishment mechanism should be established. The credit system at the national level should be perfected to guarantee credit throughout the whole social economic activities. Second, credit market subjects should be fostered at a faster pace. The government should strive to create a number of powerful credit rating agencies and credit reference agencies to provide good development conditions for these institutions, and the credit information of relevant departments should be open to these institutions. Third, the market demand for credit products should be accelerated guidance and cultivation. Relevant government departments should create a good social credit environment through government credit endorsement, making credit an indispensable part of people's daily economic activities. In the early stage of the development of shared cars, enterprises should choose to cooperate with existing credit platforms such as the people's bank of China and third-party payment companies. Meanwhile, in the process of business development, the government can establish the credit system by establishing the automobile industry association or the automobile enterprises themselves.

\section{Improving Operation Patterns}

In essence, Shared transportation is a public transportation service provided in a market-oriented manner. Operating enterprises provide some public services previously provided by the government more efficiently with public nature. However, these enterprises cannot provide supporting public services such as road construction and space allocation at the same time, which requires exploring the mode of cooperation between the government and the private sector. From the perspective of government management, the government can encourage cities to explore new governance models of cooperation between the government and the private sector in the field of shared transport. The government, the operating enterprise and other stakeholders clarify their rights and obligations, and form a win-win governance model and cooperation mechanism. The government allows eligible shared transport enterprises to enter by way of filing, and the enterprises provide such services as vehicle launching, operation and maintenance. The government is responsible for the road construction, road rights allocation and negative list of parking space. The government also needs to make dynamic optimization based on the big data of the operating companies.

\section{Expanding Profit Models}

At the present stage, the profit of car rental companies mainly depends on rental income, so widening the user group and increasing the user scale are the most effective ways to increase the income of car sharing enterprises. According to relevant statistics, the proportion of registered users under 35 years old in China reaches $80 \%$, and they are the main user group of shared cars. The rapid development of the internet time-sharing rental in China is not long, and the recognition and acceptance of consumers is not high. At the same time, because of the popularity of private cars, the demand for shared cars will not be released in a blowout in the short term. Therefore, in the process of development, the car-sharing 
enterprises should strengthen the mining and utilization of bend users and effectively divide the user groups. According to relevant data, hotel guests and college students are important target customers of shared cars, and enterprises should strengthen cooperation with universities, hotels and transportation hubs. In addition, operating enterprises can cooperate with fixed institutions, because users of such institutions usually have fixed usage requirements. Typical institutional users include government, large industrial parks, etc.

The rental income of car sharing enterprise is its main profit source at present. According to the experience of some successful enterprises at home and abroad, sharing automobile enterprises should make full use of the billing mode of "mileage plus service time". On the other hand, operating enterprises should focus on the expansion of other business income. The practice of setting up advertising space is relatively popular, including the implantation of client app, the placement of advertising in the car space and on-board Wi-Fi advertising.

\section{E. Enhancing Cooperation with Stakeholders}

First of all, in the process of operation, shared car enterprises should strengthen cooperation with the government. Enterprises and governments should establish win-win cooperation mode in promoting the development of electric vehicles. First of all, the enterprise takes the initiative to explain its related business model to the supervision department to avoid the supervision contradiction. Secondly, enterprises should share the traffic data to the regulatory authorities, which can be more conducive to urban traffic development and achieve a win-win situation. Finally, enterprises communicate with the government effectively, find the optimal regulatory scheme and share it with the government, and the government finally determines the regulatory model.

Cooperation with parking service operators needs to be strengthened. On the one hand, the operating enterprise can negotiate and communicate with the parking service providers to strengthen the renting of parking spaces in some core areas. On the other hand, the win-win cooperation pattern needs to be actively expanded. One-click parking is now widely used in parking lots of first-tier and second-tier cities. In this process, the features of shared cars can be related to the interests of oneclick parking service providers and parking lots, and solve the difficult parking problems step by step.

B-end users need to be expanded. Due to the good site and user resources, these advantages of B end users can be adopted in the cooperation process and can also be used to cooperate with some shopping malls.

The opinions of users need to be better respected. Operating companies should listen to user feedback and make improvements. Operating companies need to avoid giving away users' privacy and improve the type of car to give customers a different experience.

\section{CONCLUSION}

Under the background of the rise of sharing economy in China, shared cars have made a vigorous development. Shared cars improve the efficiency of the use of vehicle resources, alleviate the urban traffic pressure, facilitate the travel choice of consumers and help enterprises get a lot of investment. At the same time, the development of shared cars also faces a series of difficulties and challenges, such as inadequate government support, larger operating costs, higher operating risk, inconvenient parking, immature user habits, etc. This paper summarizes the development situation, business models, stakeholder relations and other issues of shared cars in China. On this basis, this paper puts forward the countermeasures and suggestions to promote the development of shared cars, such as perfecting laws and regulations, building credit system, improving operating models, expand profit patterns, strengthening the cooperation of the stakeholders, etc.

\section{REFERENCES}

[1] Namazu, M., Zhao, J., \& Dowlatabadi, H. Nudging for responsible carsharing: using behavioral economics to change transportation behavior. Transportation, vol. 45, pp.1-15, April 2018.

[2] Puschmann, T., \& Alt, R.Sharing economy. Business \& Information Systems Engineering, vol. 58, pp.93-99,January 2016.

[3] Heinrichs, H. Sharing economy: a potential new pathway to sustainability. GAIA - Ecological Perspectives for Science and Society,vol. 22, pp. 228-231, April 2013.

[4] Bellos, I., Ferguson, M., \& Toktay, L. B. The car sharing economy: interaction of business model choice and product line design. Social Science Electronic Publishing, vol. 19, pp. 28-33, February 2017.

[5] Edelman, B., Luca, M., \& Svirsky, D. Racial discrimination in the sharing economy: evidence from a field experiment. American Economic Journal Applied Economics, vol. 9, pp.1-22, February 2017.

[6] Dias, F. F., Lavieri, P. S., Garikapati, V. M., Astroza, S., Pendyala, R. M., \& Bhat, C. R. A behavioral choice model of the use of car-sharing and ride-sourcing services. Transportation, vol. 44, pp.1-17, March 2017. 